NASA's Space Launch System: A New National Capability

Todd A. May, Manager Space Launch System Program NASA Marshall Space Flight Center March 2012
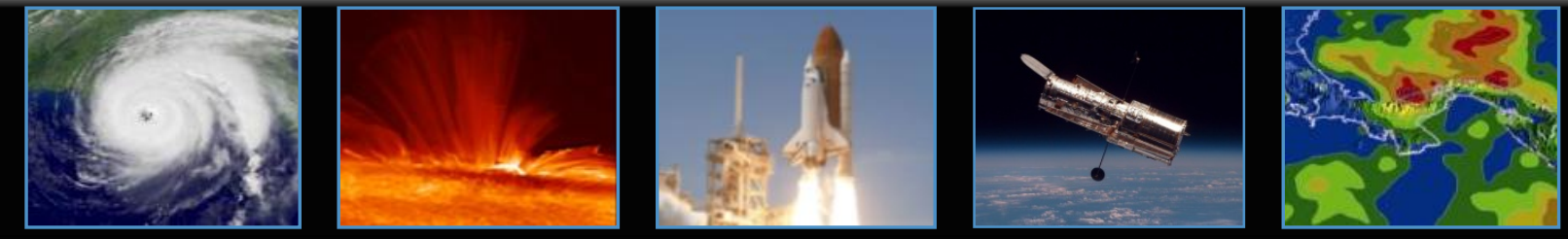

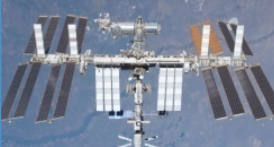

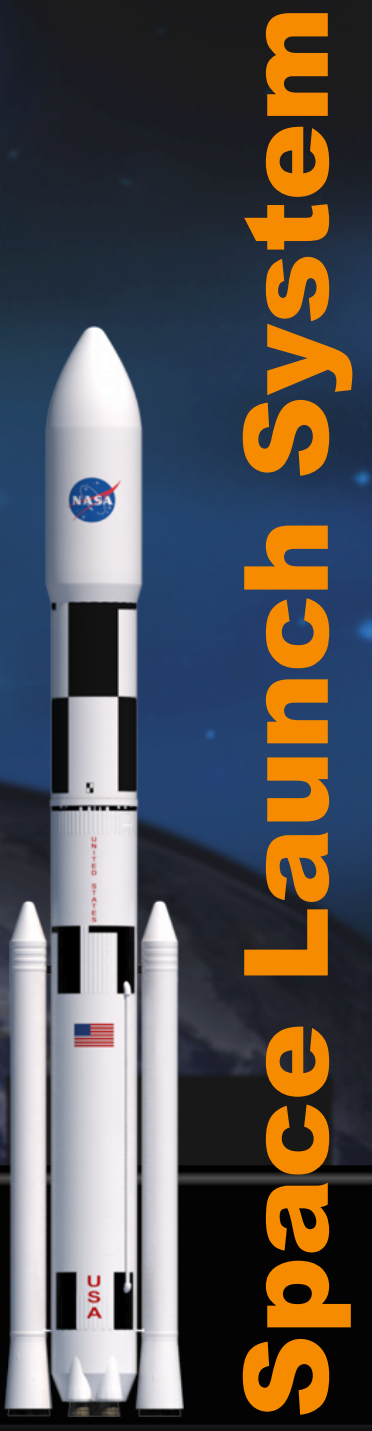




\section{The Future of Exploration}

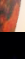

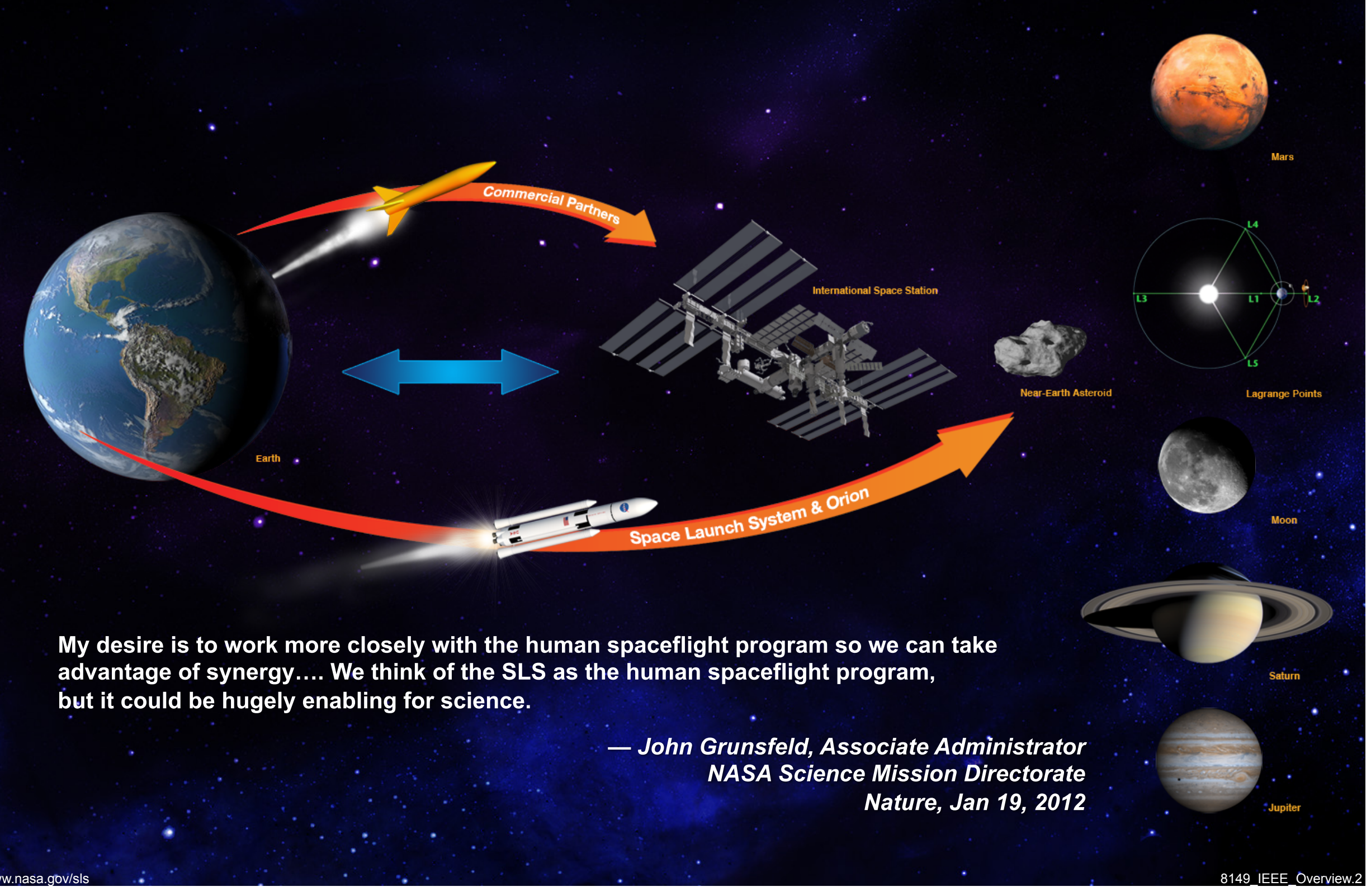




\section{Many Solutions, One Affordable-Answer}

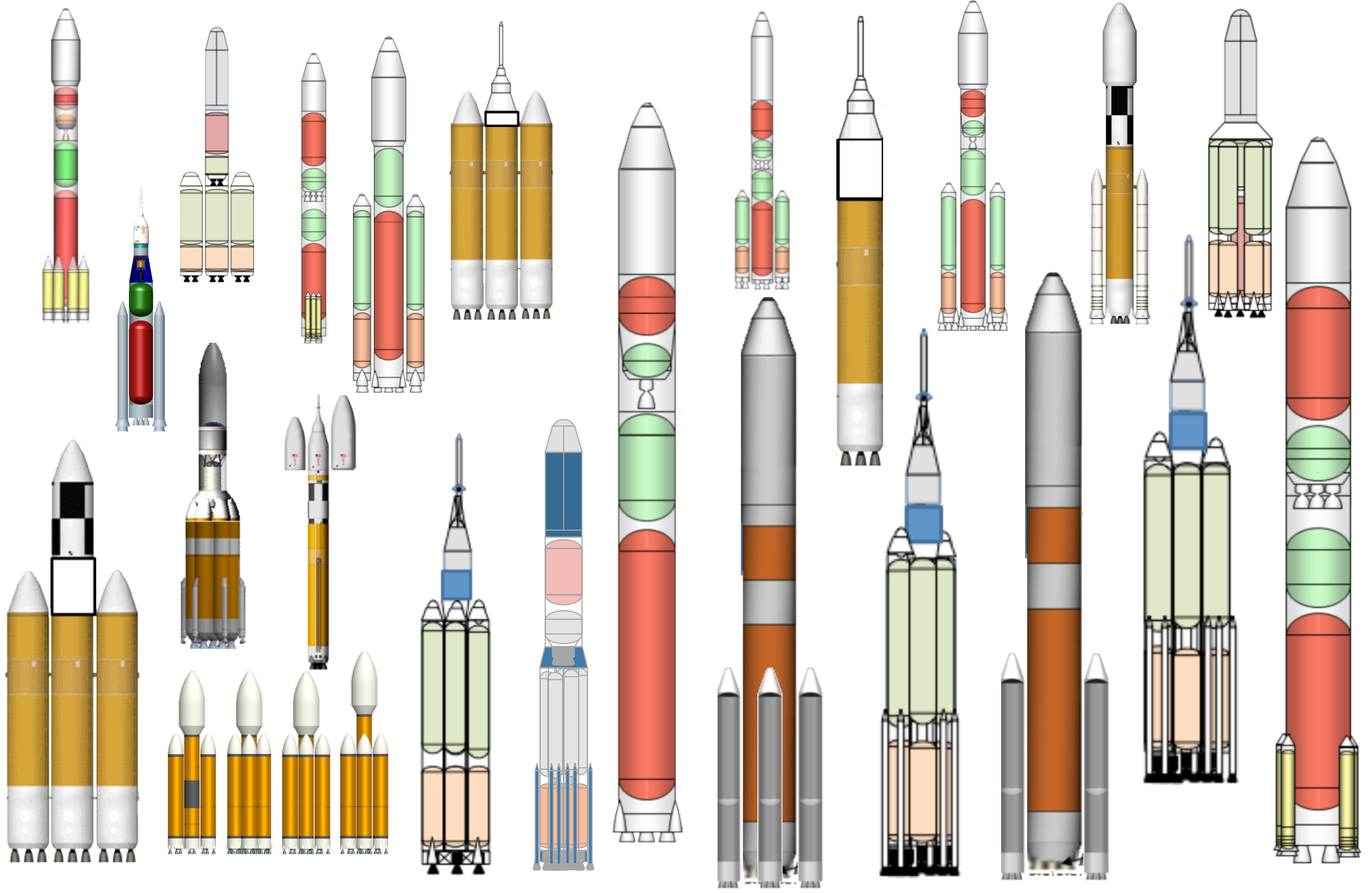

"This enterprise is not for the faint of heart."

-Wayne Hale, former Space Shuttle Program Manager 


\section{SLS Driving Objectives}

Safe: Human-Rated

Affordable

- Constrained budget environment

- Maximum use of common elements and existing assets, infrastructure, and workforce

- Competitive opportunities for affordability on-ramps

\section{Sustainable}

- Initial capability: 70 metric tons (t), 2017-2021

- Serves as primary transportation for Orion and exploration missions

- Provides back-up capability for crew/cargo to ISS

- Evolved capability: 105 t and 130 t, post-2021

- Offers large volume for science missions and payloads

- Modular and flexible, right-sized for mission requirements

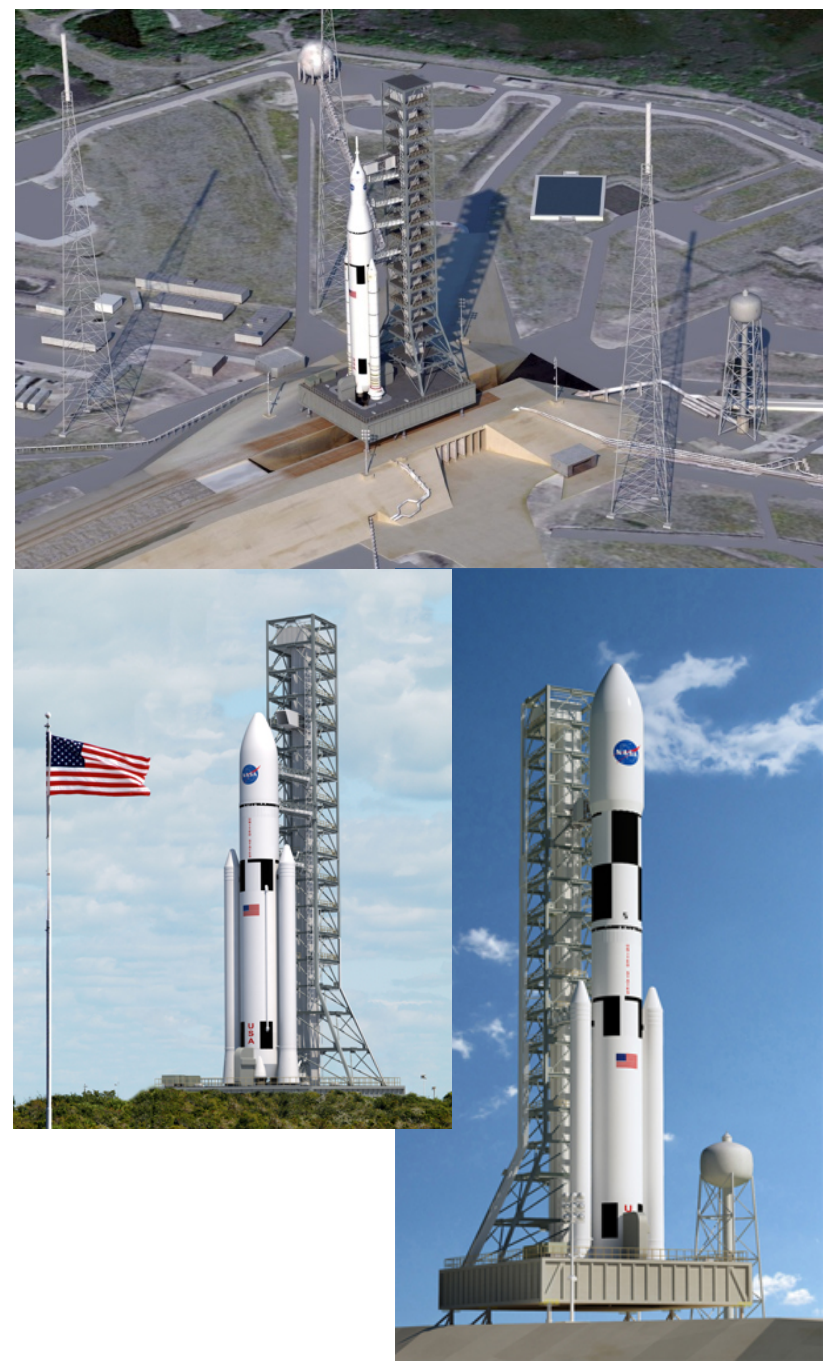

Flexible Architecture Configured for the Mission 


\section{SLS Architecture Block Upgrade Approach}

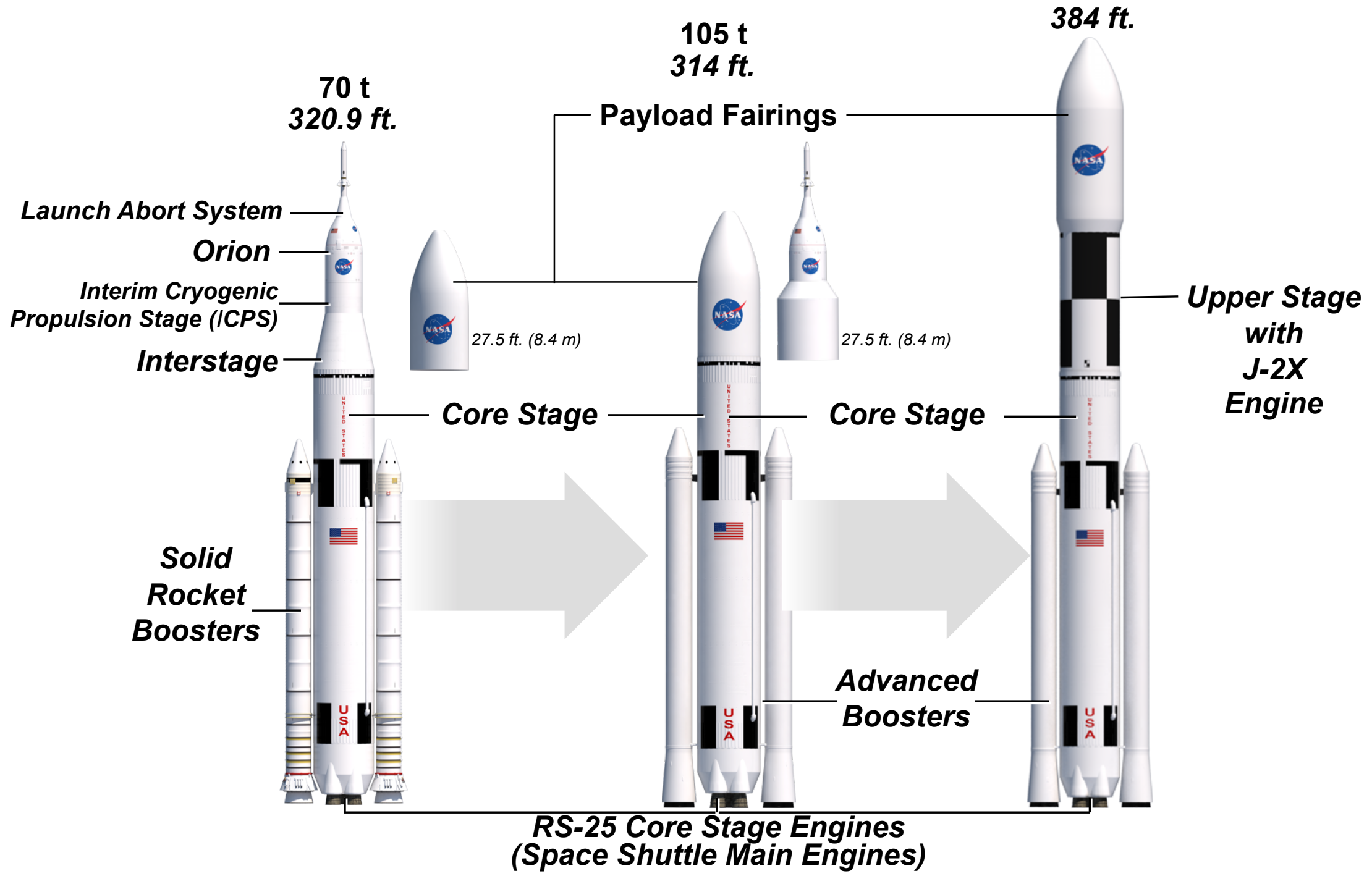




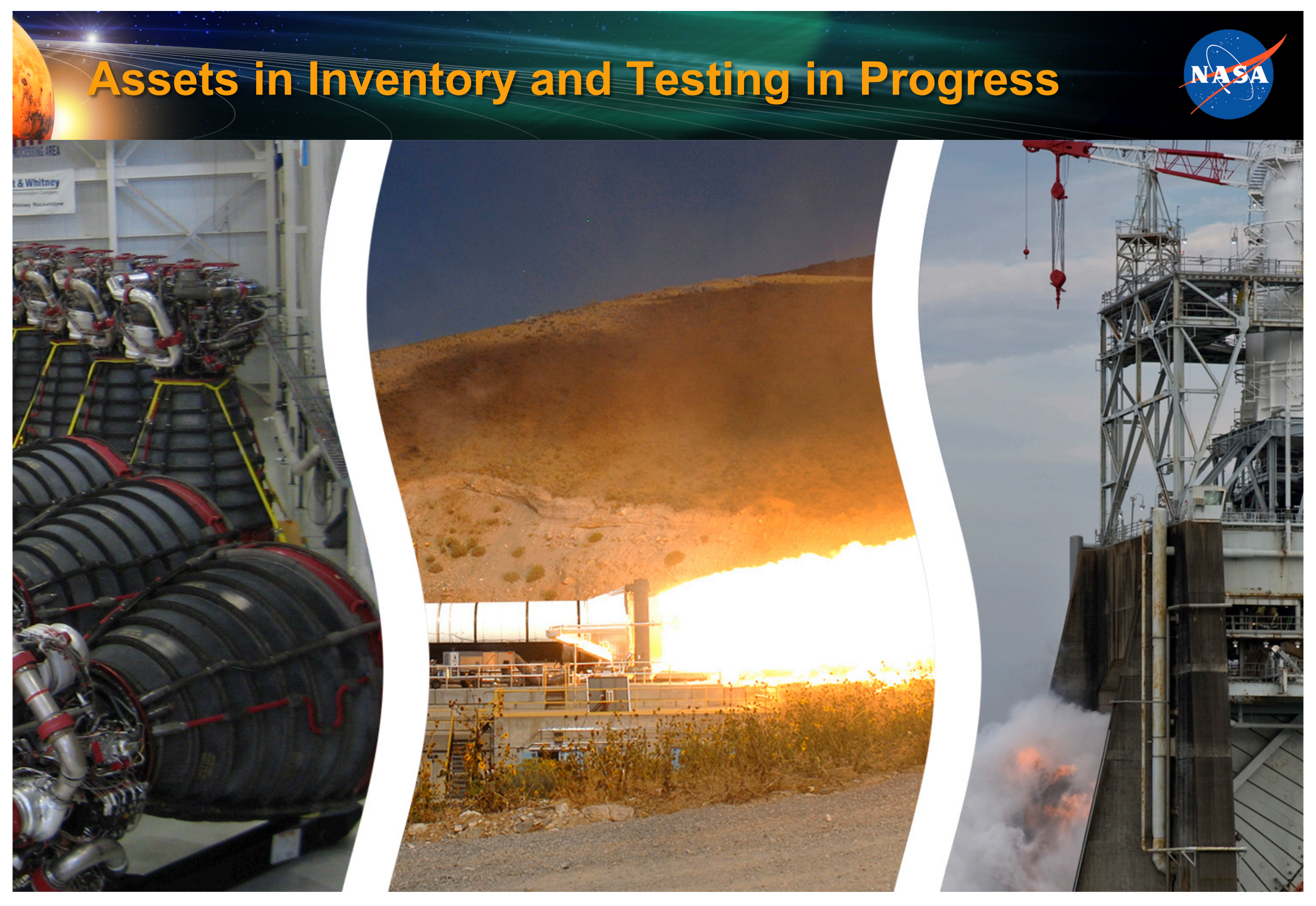

First Flight 2017 


\section{SLS Affordability Begins with Accountability}

Evolvable Development Approach

- Manage requirements within constrained, flat budgets.

- Leverage existing National capabilities, including LOX/LH $\mathrm{L}_{2}$ propulsion infrastructure, manufacturing facilities, and launch sites.

- Infuse new design solutions for affordability.

$\checkmark$ Robust Designs and Margins

- Trade performance for cost and schedule.

- Use heritage hardware and manufacturing solutions.

- Maintain adequate management reserves controlled at lower levels.

$\checkmark$ Risk-Informed Government Insight/Oversight Model

- Insight based on:

- Historic failures.

Industry partner past performance and gaps.

Complexity and design challenges.

- Judicious oversight:

- Discrete vs. near-continuous oversight.

Timely and effective decisions.

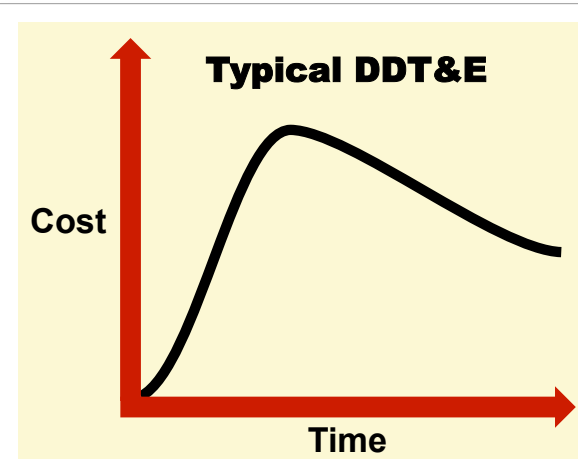

Sustainability Through Life-Cycle Affordability

Affordability: The ability to develop and operate the SLS within the National means,

\section{Risk-Informed Government}

Insight/Oversight Model

- Insight based on:

Historic failures.

Industry partner past performance and gaps.

Complexity and design challenges.

- Judicious oversight:

Discrete vs. near-continuous oversight.

Timely and effective decisions.

Right-Sized Documentation and Standards

- Up to $80 \%$ reduction in the number of Data Requirement (DR) and Program documents from the Ares Projects.

- Industry practices and tailored NASA standards.

Lean, Integrated Teams with Accelerated Decision Making

- Simple, clear technical interfaces with contractors.

- Interconnected Systems Engineering \& Integration (SE\&I) organization.

- Empowered decision makers at all levels.

- Fewer Control Boards and streamlined change process.

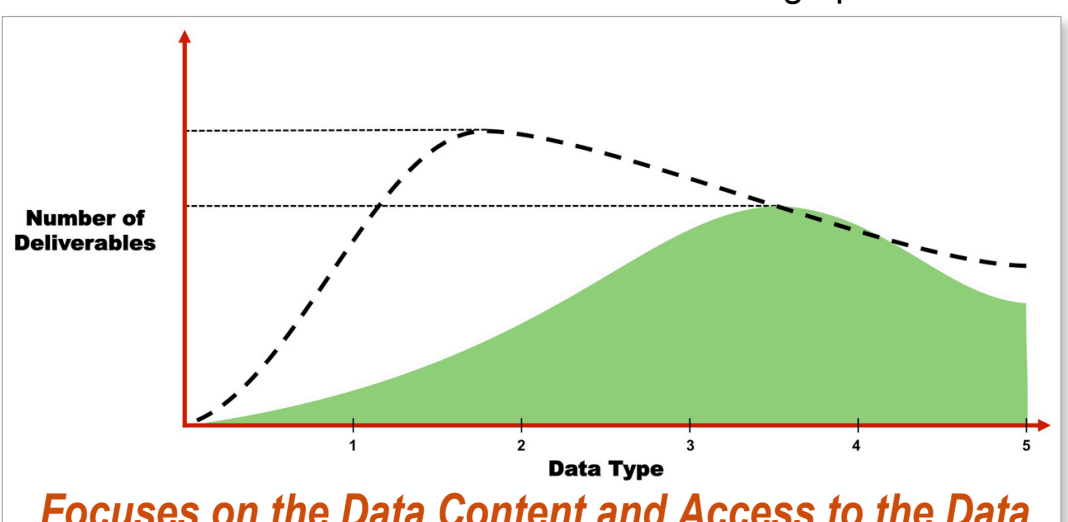

SLS DDT\&E

Cost

Time

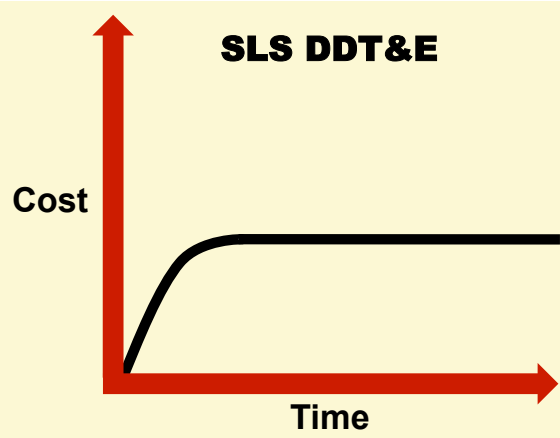

Focuses on the Data Content and Access to the Data

49_IEEE_Overview.7 


\section{cost is a Function of Performance}

Extreme requirements drive up costs by $215 \%$.

Question: Is a $14 \%$ increase in maximum speed (performance) worth a $215 \%$ increase in cost?

Question: Is a $28 \%$ increase in $0-60 \mathrm{mph}$ acceleration (performance) worth a $215 \%$ increase in cost?

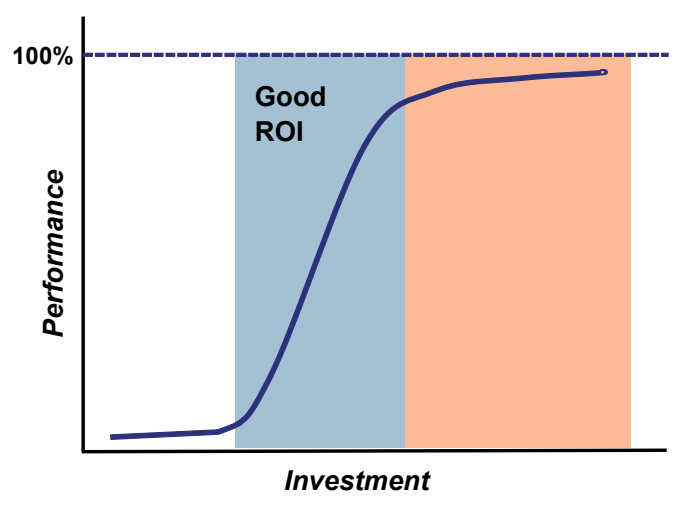

\section{Porsche 911 Carrera}

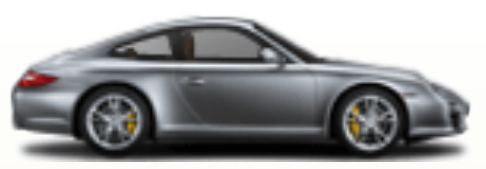

Cylinders

Engine layout

Performance

0-60 mph

MSRP
6

Rear

$180 \mathrm{mph}$

$4.7 \mathrm{sec}$

$\$ 77,800$
Porsche 911 Turbo

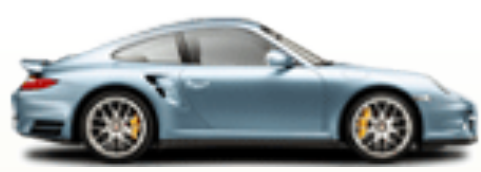

Cylinders

Engine layout

Performance

0-60 mph

MSRP
6

Rear

$195 \mathrm{mph}$

$3.5 \mathrm{sec}$

$\$ 160,700$
Porsche 911 GT2 RS

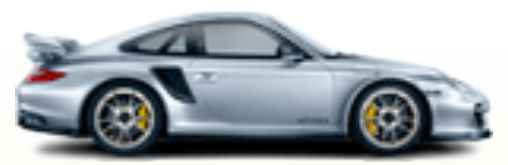

- Source: Porsche website

\section{Cylinders}

Engine layout

Performance

6

Performance

MSRP

Horsepower 620
Rear

$205 \mathrm{mph}$

$3.4 \mathrm{sec}$

$\$ 245,000$

\section{We Will Factor the Real Cost into Our Decisions}




\section{The Real Cost of Launch Vehicle-Development}

$\checkmark$ Affordability requirements demand that we develop the SLS in a faster and more efficient manner, including the decision-making process.

$\checkmark$ We cannot afford to delay decisions ... or delay getting behind them!

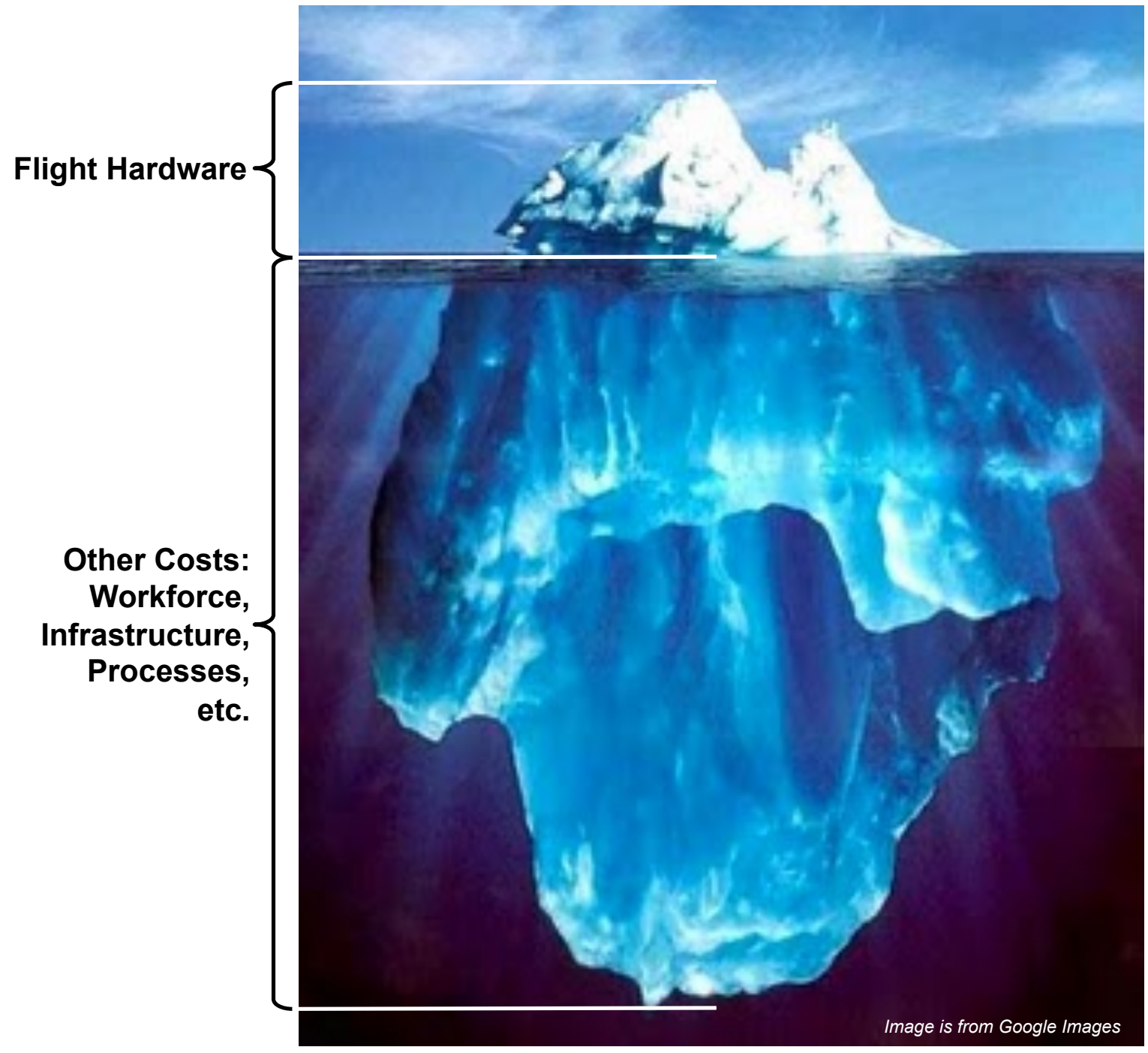

Time Is The One Resource That We Can Never Regain 


\section{Jnitial Exploration Missions (EM)}

\section{EM-1}

- Un-crewed circumlunar flight - free return trajectory

- Mission duration $\sim 7$ days

- Demonstrate integrated spacecraft systems

performance prior to crewed flight

- Demonstrate high speed entry $(\sim 11 \mathrm{~km} / \mathrm{s})$ and Thermal

Protection System prior to crewed flight

- SLS Block 1: two 5-segment SRBs, four RS-25 core stage engines

- Interim Cryogenic Propulsion Stage (ICPS)

- Launch from Kennedy Space Center (KSC) Launch Complex (LC) 39B
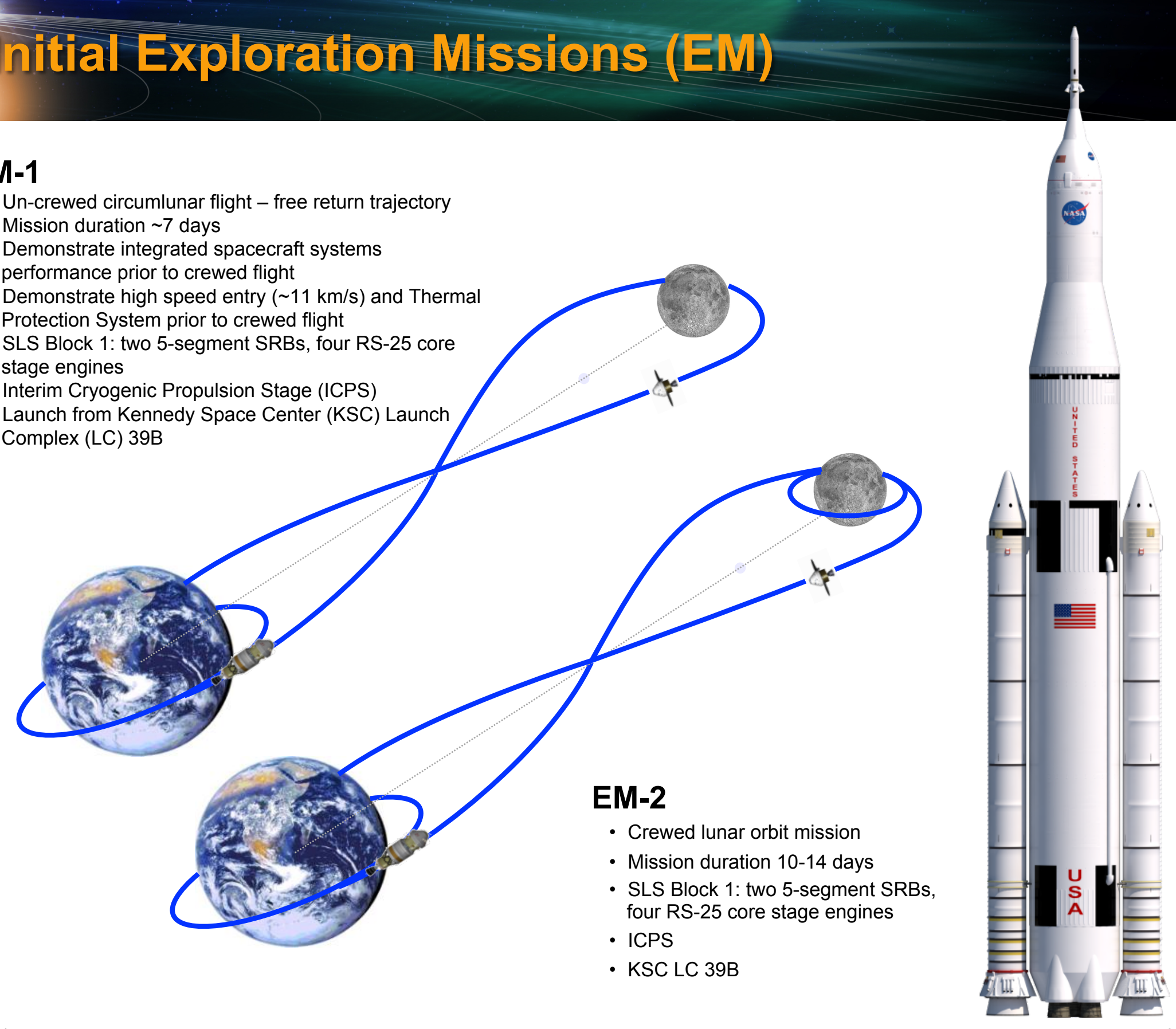


\section{NASA's Space Launch System Summary}

Vital to NASA's exploration strategy and the Nation's space agenda.

Key tenets: safety, affordability, and sustainability.

System Requirements Review/System Definition Review in progress.

Prime contractors on board, engaging the U.S. aerospace workforce.

$\checkmark$ RS-25 core stage engines positioned for integration and testing with the core stage.

$\checkmark$ Five-segment solid rocket booster and $\mathrm{J}-2 \mathrm{X}$ upper stage engine testing in progress.

Competitive opportunities for innovations that affordably upgrade performance.

$\checkmark$ On track for first flight in 2017.

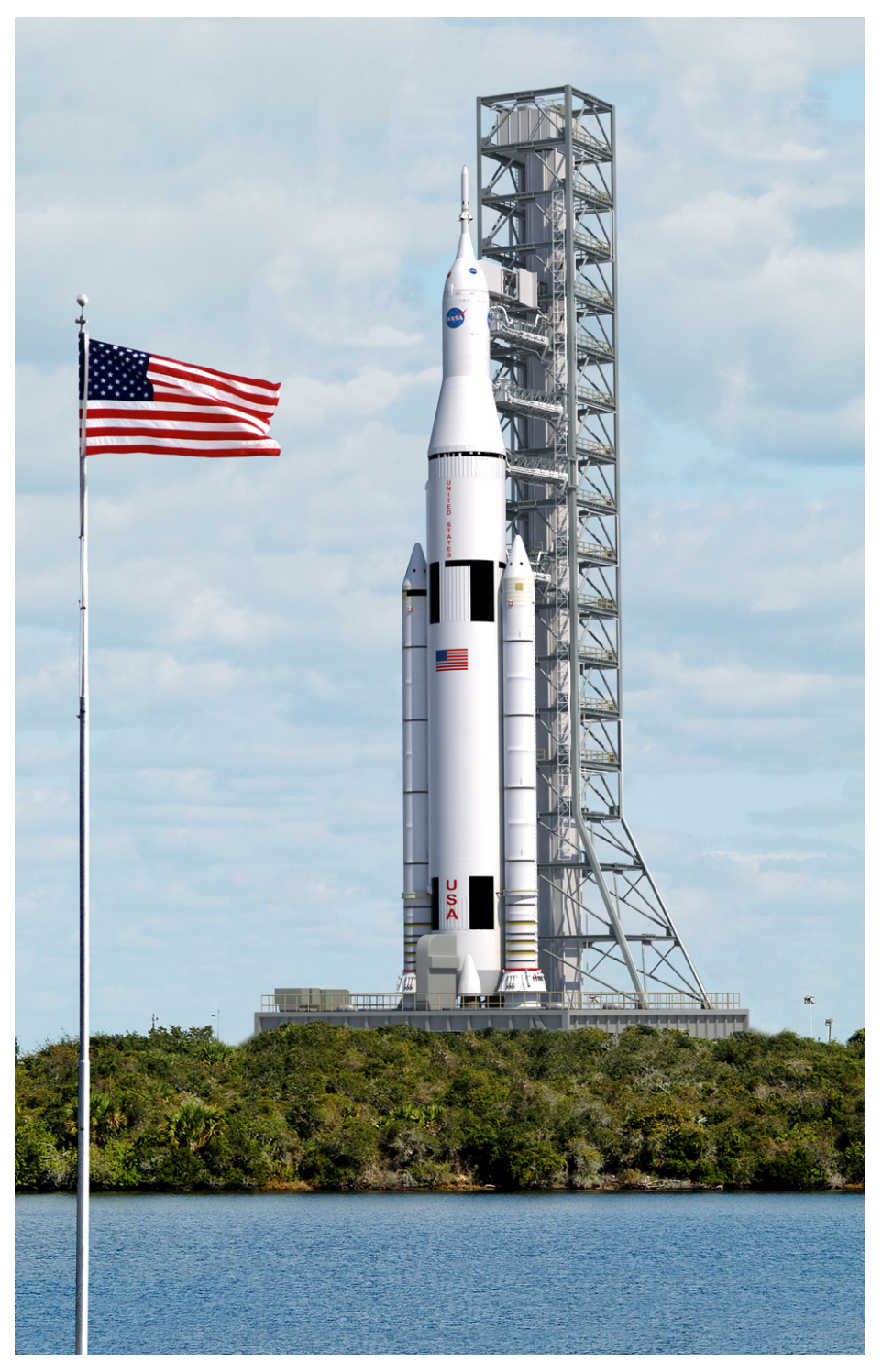


For More Information www.nasa.gov/s/s 